\title{
Correlation between Length of Life and Exposure to Air Pollution
}

\author{
Anna Spychała, Joanna Domagalska*, Małgorzata Ćwieląg-Drabek, \\ Ewa Marchwińska-Wyrwal
}

\author{
Department of Environmental Health, School of Public Health in Bytom, \\ Medical University of Silesia in Katowice, Poland
}

Received: 31 October 2018

Accepted: 12 January 2019

\begin{abstract}
According to the World Health Organization, air pollution contributes to shortened life expectancies of UE citizens by an average of 8.6 months. The aim of our study was to see if there is a relationship between exposure of inhabitants of cities to air pollution and the length of their lives, excluding deaths caused by external causes. Average annual concentrations of air pollutants such as $\mathrm{PM}_{10}$, benzo(a)pyrene, cadmium and lead in $\mathrm{PM}_{10}$ were based on data from the measuring stations, while the concentrations of dioxins, furans and polychlorinated biphenyls were their own measurements. The average women's and men's life expectancies in 11 cities in the year 2015, after excluding accidents and suicides, were calculated on the basis of the registry of deaths. Inequalities in men's and women's life expectancies are significant between cities and there is a relationship between exposure to air pollutants and the length of men's and women's lives in each city, demonstrating a very strong correlation in the male population. An effective tool for identifying significant risk factors affecting human health seems to be the multiple regression model.
\end{abstract}

Keywords: life length, health inequalities, long-term exposure, air pollution, multiple regression

\section{Introduction}

The health status of the population is determined by health indicators, among which one of the most important is the average life expectancy. Life expectancy indicates general health efficiency in a society at a given time and reflects the reduction of mortality rates in all age groups, including such factors as: increasing living standards and education levels, a healthier lifestyle and better access to quality health services [1].

*e-mail: jdomagalska@sum.edu.pl
This indicator has its source in the mortality statistics and it expresses the average number of years, which person coming from a specific population at the age of $\mathrm{x}$ completed years, in a defined mortality condition is expected to live $[2,3]$. To calculate the average life expectancy, there is a need to use mortality data, which can be classified into one of five basic causes of death: cardiovascular diseases, cancer, external causes of injuries and poisoning, respiratory diseases and diseases of the digestive system [4].

According to the International Statistical Classification of Diseases and Related Health Problems ICD-10, the group of external causes of diseases and deaths includes: accidents (including traffic accidents 
and other external causes of accident injuries), intentional self-injuries, assaults, complications of medical and surgical procedures, and consequences of external causes of illness and death [5]. In accordance with the official statistics, deaths caused by external causes are the third cause of death in Poland (after cardiovascular and cancer diseases), which can significantly affect the picture of the air pollution impact on life length [6]. It seems reasonable to use such measures of life expectancy, which includes only deaths from natural causes - as the real life length.

The average life expectancy between the EU Member States in the years 1980-2016 was very diverse, with a systematically growing tendency. In this period they increased by over 5 years. According to the Eurostat data, life expectancy at birth in the EU in 2016 amounted to 81.0 years (83.6 years for women and 78.2 years for men). In the years 2000-2016, the increase in life expectancy for men in EU Member States ranged from 2.8 years (in Lithuania) to 7.7 years (in Estonia), and among women from 2.1 years (in Sweden) to 5.8 years (in Estonia). In 2016, the differences between the highest and the lowest life expectancies among EU countries were 11.5 years for men and 7.8 for women. In the male population, the lowest value of the indicator was recorded in Lithuania (69.5 years), and the highest in Italy (81.0 years). The lowest life expectancy in the population of women was shown in Bulgaria (78.5 years), and the highest in Spain (86.3 years). In Poland, life expectancy is clearly shorter than the average in the EU countries; men live about 4.3 years less, and women about 1.6. In 2016, male residents lived an average 73.9 years and females about 8.0 years longer (82 years) [7]. The current life expectancy of Poles is equal to that, which occurred 17 years ago in 15 countries of the European Union [8].

The problem of health inequalities is a major challenge for public health in Europe and around the world, and the World Health Organization (WHO) emphasizes the importance of the environment as a very crucial determinant of health. According to WHO and the International Agency for Research on Cancer (IARC), air pollution contributes to shortening the average life expectancy of the EU Member States by an average of 8.6 months - up from about 3 months in Finland and Ireland to more than 13 months in Belgium. Additionally, the correlation between exposure to air pollution and increased incidence of cancer diseases, in particular lung cancer, as well as respiratory and cardiovascular diseases in the European population, has been proven $[1,9,10]$.

The aim of our study was to investigate the relationship between long-term exposure to the mixture of air pollutants such as: particulate matter $\mathrm{PM}_{10}$, benzo(a)pyrene, cadmium and lead as well as dioxins, furans and polychlorinated biphenyls, and the life length of inhabitants of selected cities of Silesia Province.

A study of the correlation between life length and long-term exposure to air pollution should include populations with comparable population sizes living in areas with different levels of air pollution.

\section{Material and Methods}

The research material were data on concentrations of selected air pollutants and epidemiological data concerning the real-life expectancies of women and men from selected cities with county rights in Silesia Province, Poland.

The research was carried out on the basis of life length data of inhabitants from 11 selected cities with county rights in Silesia Province (Bytom, Chorzów, Dąbrowa Górnicza, Gliwice, Jaworzno, Katowice, Ruda Śląska, Rybnik, Sosnowiec, Tychy and Zabrze). These are the cities where population is around $100000+$ inhabitants. The average population of women and men across 11 cities in this period of time was 1752477 people (840 418 men and 912059 women) [11].

Data on average annual $\mathrm{PM}_{10}$ concentration of suspended particulate matter and benzo(a)pyrene, cadmium and lead adsorbed on it, for the years 1989-2008, were obtained from the Provincial Sanitary-Epidemiological Station in Katowice and the Provincial Environmental Protection Inspectorate in Katowice.

State Environmental Monitoring does not carry out measurements of air pollution with dioxins, furans and polychlorinated biphenyls (PCBs). Consequently, our own measurements of the concentrations of these compounds in the air were conducted during the period between December 2014 and February 2015 using the passive air sampling method. The samples were analysed by the certified testing laboratory of E\&H Services, A.S. (Czech Republic). Certificate of accreditation No. 4/2016 was issued on the basis of the assessment of fulfilment of the accreditation criteria in accordance with CSN EN ISO/IEC 17025:2005.

Concentration levels of air pollutants in the analysed cities, for example $\mathrm{PM}_{10}$, were very diverse. In extreme cases, the lowest average concentration of $\mathrm{PM}_{10}$, for the years 1989-2002, was recorded in Dąbrowa Górnicza $\left(80.79 \mu \mathrm{g} / \mathrm{m}^{3}\right)$, while the highest was in Chorzów $\left(112.57 \mu \mathrm{g} / \mathrm{m}^{3}\right)$. In the next 6 years $(2003-2008)$, the average concentration values of suspended particulate matter in the air were almost twice lower, obtaining the lowest value in Jaworzno $\left(44.0 \mu \mathrm{g} / \mathrm{m}^{3}\right)$, and the highest in Zabrze $\left(71.67 \mu \mathrm{g} / \mathrm{m}^{3}\right)$.

The Central Statistical Office of Poland made available data on the number of deaths, including gender and age of the deceased, and the causes of deaths (according to the International Statistical Classification of Diseases and Related Health Problems ICD-10) in selected cities with county rights in Silesia Province in the years 2002-2015. These data were used to calculate the real life length and life length excluding deaths caused by external causes. 
The real life length was calculated using the following equation:

$=\frac{\text { the number of years lived by people who died in a specific year }}{\text { number of people who died in a specific year }}$

The life length (excluding deaths caused by external causes) was calculated using the following equation:

$=\frac{\begin{array}{c}\text { the number of years lived by people who died in a specific year } \\ \text { (excluding deaths caused by external causes) }\end{array}}{\text { number of people who died in a specific year }}$

In the regression analysis we focused on data from 11 cities. The relative cumulative exposure values for $\mathrm{PM}_{10}, \mathrm{BaP}$ and cadmium, over the period 1989-2008, were calculated by taking the lowest value found among all cities over the study period (set to 1 ) and converting all other values to multiples of this value. To get a cumulative value for each city in all years, the values for each year were summed. Because the dioxins (PCDDs), furans (PCDFs), dioxin-like polychlorinated biphenyls (dl-PCBs) and non-dioxin-like polychlorinated biphenyls (ndl-PCBs) were measured at one point in time (in 2014 or 2015), the cumulative exposure score was not calculated. Relative exposure values were calculated by taking the lowest measurement for each pollutant (set to 1) and converting all other values to multiples of this value.

Collected epidemiological data (life length, excluding deaths caused by external causes) and air pollution data were evaluated for normal distribution by the Shapiro-Wilk test with a confidence level of $95 \%$. A multiple regression analysis was carried out to assess the combined effect of pollutants on men's and woman's life expectancies. All analyses were carried out using a threshold for statistical significance set at a value of $\mathrm{p} \leq 0.05$. Statistical analysis of the collected material was carried out using Microsoft Office (MS Word, MS Excel, MS Access) and Statistica 12 StatSoft Poland, with the addition of the medical kit.

\section{Results and Discussion}

The average life expectancy is one of the basic measures of population health status. The methodology used to calculate this indicator is recommended by the World Health Organization, which provides the possibility to compare the average life expectancy between countries in the world. This methodology is also used in Poland. In order to investigate the relationship between long-term exposure to air pollution with $\mathrm{PM}_{10}$ suspended dust and the mixture of compounds adsorbed on it as well as dioxins, furans and polychlorinated biphenyls, the life expectancy of Silesian inhabitants was used. The results in Table 1 show the differences between the commonly used life expectancy values and the real life length excluding the deaths from external causes.
Average life expectancy, life length and life length excluding the deaths from external causes are measures related to life expectancy, but the values of these indicators are clearly different. Table 1 presents their comparison in the population of women and men in selected cities of Silesia Province in 2002. The biggest difference between average life expectancy and life length, both in the population of women and men, was demonstrated in Zabrze: 12.8 and 10 years, respectively.

The percentage of external causes of deaths in total mortality in the analysed population from selected cities was significantly higher in the male population (7.7-11.4\%) compared to women (3-6.5\%). The highest value, both among men and women, was recorded in Dąbrowa Górnicza. Among the inhabitants of Gliwice and the male population of Jaworzno, external causes constituted the smallest percentage of total mortality (Table 1).

On the basis of the data contained in Table 2, the life length of the population from selected cities in 2015 was compared. In case of both analyzed measurement, among the population of women and men, the longest life length was demonstrated in Gliwice, and the shortest in Ruda Śląska. Table 2 also indicates the percentage share of external causes of death in total mortality. In the female population, external causes accounted for $1.9-4.1 \%$, and in the male population $5-7 \%$ of total deaths in the analysed cities.

The health efficiency of the society of 11 cities with county rights in Silesia Province, living in conditions of long-lasting diversification between cities' air pollution, was referenced to the life length. The research shows that not the commonly used average life expectancy but actual life length should be taken into account when looking for the relationship between exposure to air pollution and life length. The average real life length in the population of women and men was obtained on the basis of mortality from natural causes, after excluding deaths classified by ICD-10 to deaths caused by external causes (V01-Y98) [5].

According to the data presented in Tables 1 and 2, deaths due to external causes understate the average life length for men and women, causing it to be lower than life expectancy calculated for the same population. Furthermore, the higher death rate due to external causes affects men, which increases the existing difference between the average life expectancy depending on gender. Considering that the share of external causes of death in total mortality may constitute an interference factor in the study investigating the impact of air pollution on the life length of population, for statistical analyses, life length (excluding deaths caused by external causes) was taken into account.

Comparison of life expectancy in the EU countries indicates a large discrepancy between member states as well as between individual regions in these countries $[7,12]$. One of the inequality causes in life expectancy may be environmental pollution - especially air pollution. Recent studies confirm the relationship 


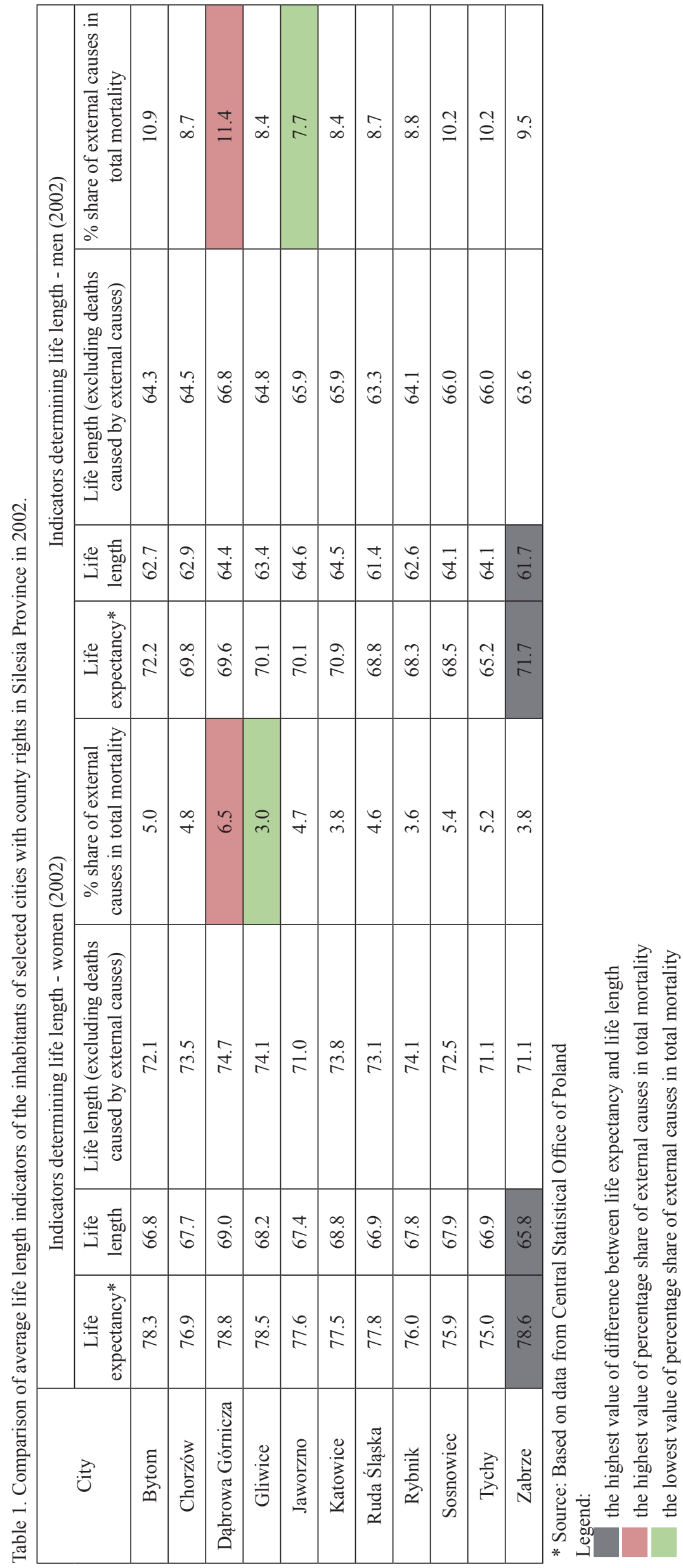


Table 2. Comparison of average life length indicators of inhabitants of selected cities with county rights in Silesia Province in 2015.

\begin{tabular}{|c|c|c|c|c|c|c|}
\hline \multirow{2}{*}{ City } & \multicolumn{3}{|c|}{ Indicators in women population (2015) } & \multicolumn{3}{|c|}{ Indicators in men population (2015) } \\
\cline { 2 - 7 } & $\begin{array}{c}\text { Life } \\
\text { length }\end{array}$ & $\begin{array}{c}\text { Life length (exclud- } \\
\text { ing deaths caused by } \\
\text { external causes) }\end{array}$ & $\begin{array}{c}\text { \% share of } \\
\text { external causes } \\
\text { in total mortality }\end{array}$ & $\begin{array}{c}\text { Life } \\
\text { length }\end{array}$ & $\begin{array}{c}\text { Life length (exclud- } \\
\text { ing deaths caused by } \\
\text { external causes) }\end{array}$ & $\begin{array}{c}\text { \% share of } \\
\text { external causes in } \\
\text { total mortality }\end{array}$ \\
\hline Bytom & 74.3 & 74.3 & 2.5 & 67.2 & 68.3 & 6.4 \\
\hline Chorzów & 76.1 & 76.4 & 3.8 & 67.9 & 68.9 & 6.2 \\
\hline Dąbrowa Górnicza & 75.4 & 75.7 & 2.9 & 68.0 & 68.9 & 6.1 \\
\hline Gliwice & 76.9 & 77.0 & 3.2 & 69.0 & 70.1 & 6.3 \\
\hline Jaworzno & 75.4 & 75.8 & 3.8 & 68.8 & 69.5 & 5.0 \\
\hline Katowice & 76.1 & 76.4 & 3.8 & 68.4 & 69.5 & 7.0 \\
\hline Ruda Śląska & 74.1 & 74.1 & 4.1 & 65.9 & 66.9 & 6.8 \\
\hline Rybnik & 76.1 & 76.5 & 3.0 & 67.4 & 68.4 & 6.5 \\
\hline Sosnowiec & 76.0 & 76.2 & 3.3 & 67.4 & 68.3 & 6.8 \\
\hline Tychy & 75.5 & 75.7 & 1.9 & 69.0 & 69.9 & 6.3 \\
\hline Zabrze & 74.7 & 75.0 & 3.5 & 66.4 & 67.5 & 6.1 \\
\hline
\end{tabular}

Legend:

the lowest value of life length (excluding deaths caused by external causes)

the highest value of life length (excluding deaths caused by external causes)

the highest value of percentage share of external causes in total mortality

the lowest value of percentage share of external causes in total mortality

between the exposure of residents to air pollution, the length of exposure and the occurrence of chronic diseases, and therefore the impact on length of life [13-17]. According to WHO data, in $201691 \%$ of the world's population lived and worked in places where the WHO air quality guidelines were not met. It is estimated that in 2016 outdoor air pollution in cities and in rural areas caused 4.2 million premature deaths worldwide. About $91 \%$ of these premature deaths occurred in low- and middle-income countries, and the largest in Southeast Asia and the region of the Western Pacific [18]. By lowering the level of air pollution, countries can reduce the burden of chronic diseases such as lung cancer, stroke, heart diseases, and respiratory diseases.

The conducted research shows that similarly to Silesia Province, the reduction of air pollution could significantly reduce the number of chronic diseases. Silesia is characterized by the emission of significant amounts of air pollutants into the atmosphere from both numerous industrial sources and households, heated with coal or other fuels, often of poor quality.

Data on concentrations of $\mathrm{PM}_{10}$, cadmium and benzo(a)pyrene in suspended dust fraction $\mathrm{PM}_{10}$ were rearranged in relation to the minimum values recorded in 2008 (the year with the lowest values in the 20 -year

Table 3. Modeling the correlation between the mixture of air pollutants and the life length of men (excluding deaths caused by external causes) in Silesia Province in 2015; multiple regression using ranking in relation to the lowest average value of air pollution.

\begin{tabular}{|c|c|c|c|}
\hline \multicolumn{4}{|c|}{$\begin{array}{c}R=0.95056931 \\
R^{2}=0.90358201 \\
p<0.048\end{array}$} \\
\hline Variables & beta \pm statistical error beta & $B \pm$ statistical error $B$ & $\mathbf{p}$ \\
\hline $\mathbf{P M}_{10}$ & $-3.563 \pm 0.716$ & $-0.512 \pm 0.102$ & 0.007 \\
\hline $\mathrm{Cd} w \mathrm{PM}_{10}$ & $0.755 \pm 0.327$ & $0.017 \pm 0.007$ & 0.082 \\
\hline $\mathrm{B}(\mathrm{a}) \mathrm{P}$ w $\mathrm{PM}_{10}$ & $2.88 \pm 0.728$ & $0.120 \pm 0.030$ & 0.167 \\
\hline $\mathrm{PCDD} / \mathrm{F}$ & $0.811 \pm 0.213$ & $2.086 \pm 0.549$ & 0.191 \\
\hline dl-PCBs & $-0.421 \pm 0.257$ & $-0.652 \pm 0.397$ & 0.017 \\
\hline ndl-PCBs & $-0.680 \pm 0.284$ & $-0.568 \pm 0.238$ & 0.007 \\
\hline
\end{tabular}


Table 4. Modeling the correlation between the mixture of air pollutants and the life length of women (excluding deaths caused by external causes) in Silesia Province in 2015; multiple regression using ranking in relation to the lowest average value of air pollution.

\begin{tabular}{|c|c|c|c|}
\hline \multicolumn{4}{|c|}{$\begin{array}{c}\mathbf{R}=\mathbf{0 . 8 5 5 9 0 6 2 1} \\
\mathbf{R}^{2}=\mathbf{0 . 7 3 2 5 7 5 4 4} \\
\mathbf{p}<\mathbf{0 . 0 2 9}\end{array}$} \\
\hline Variables & beta \pm statistical error beta & $B \pm$ statistical error $B$ & $\mathbf{p}$ \\
\hline $\mathrm{PM}_{10}$ & $-3.364 \pm 1.193$ & $-0.451 \pm 0.160$ & 0.047 \\
\hline $\mathrm{Cd} \mathrm{w} \mathrm{PM}_{10}$ & $0.232 \pm 0.545$ & $0.005 \pm 0.012$ & 0.629 \\
\hline $\mathrm{B}(\mathrm{a}) \mathrm{P}$ w $\mathrm{PM}_{10}$ & $3.426 \pm 1.213$ & $0.133 \pm 0.047$ & 0.476 \\
\hline $\mathrm{PCDD} / \mathrm{F}$ & $0.668 \pm 0.355$ & $1.604 \pm 0.853$ & 0.133 \\
\hline dl-PCBs & $-0.707 \pm 0.428$ & $-1.021 \pm 0.618$ & 0.017 \\
\hline ndl-PCBs & $-0.511 \pm 0.474$ & $-0.399 \pm 0.370$ & 0.341 \\
\hline
\end{tabular}

exposure period) in the cities selected for research. The final value, used in the multiple regression model, was the sum of the annual multiplicities of the minimum concentration value for each pollutant tested in each city over a 20-year period (1989-2008). Data on the concentrations of dioxins, furans and polychlorinated biphenyls were compared to the smallest values recorded during the heating period at the turn of 2014 and 2015.

Considering the simultaneous occurrence of all analyzed factors whose average concentrations have been set in relation to the lowest average value, the results of multiple regression suggested that the combined effect of the inhalation exposure to the mixture consisting of dioxin-like polychlorinated biphenyls (dl-PCBs), nondioxin-like polychlorinated biphenyls (ndl-PCBs) and particulate matter $\mathrm{PM}_{10}$ were expressed with reduced life length of men, and this relationship was statistically significant. The calculated correlation was almost perfect $(\mathrm{R}=0.95)$ (Table 3$)$.

The foregoing model showed that reducing the average annual $\mathrm{PM}_{10}$ concentration by $29 \mu \mathrm{g} / \mathrm{m}^{3}$ of air (the lowest value of which is the basis for ranking cities in relation to particulate matter pollution) could extend life length of men by more than half a year ( 0.51 years). Additionaly, reducing air pollution with dioxin-like PCB compounds by $4.3 \mathrm{fg} \mathrm{I}-\mathrm{TEQ} / \mathrm{m}^{3}$ of air (the lowest value which is the basis for ranking cities in relation to dl-PCBs), can extend men's life length by almost 8 months (0.66 years), and non-dioxin-like PCB compounds by $17.5 \mathrm{pg} / \mathrm{m}^{3}$ of air (the lowest value of which is the basis for ranking cities in relation to ndl-PCBs) by almost 7 months ( 0.57 years).

Considering the simultaneous occurrence of all analysed factors whose average concentrations have been set in relation to the lowest average value, the multiple regression model showed a statistically significant impact of air pollution on life length (excluding deaths caused by external causes) among women in selected cities with county rights in Silesia Province (Table 4).

The analysis showed that reducing the average annual $\mathrm{PM}_{10}$ concentration by $29 \mu \mathrm{g} / \mathrm{m}^{3}$ of air (the lowest value of which was the basis for ranking cities in relation to particulate matter pollution) could extend women's life length by almost 6 months ( 0.45 years). Furthermore, reducing air pollution with dioxin-like PCB compounds by $4.3 \mathrm{fg} \mathrm{I}-\mathrm{TEQ} / \mathrm{m}^{3}$ of air (the lowest value which was the basis for ranking cities in relation to dl-PCBs) could extend women's life length by about a year (1.02 years).

A similar relationship was shown by other researchers, indicating that reduction of $\mathrm{PM}_{10}$ suspended particulate matter by $1 \mu \mathrm{g} / \mathrm{m}^{3}$ extends the life expectancy of men by 0.1 years [19]. The Aphekom project has shown that reducing airborne $\mathrm{PM}_{2,5}$ to levels indicated by WHO could prevent 19000 cases of premature deaths [20]. According to Nigerian and Indian researchers, the life expectancy of their respective countries' inhabitants could increase after the reduction of air pollution to the WHO value, depending on the initial concentration of particulate matter in the region, by about 1.6-2.9 years [21] and 2-9 months [22]. Research conducted by Pope et al. showed that in 1970-2000 in cities in the United States, the concentration of particulate matter was reduced by $10 \mu \mathrm{g} / \mathrm{m}^{3}$ of air, which resulted in a longer life expectancy of $0.61 \pm 0.2$ years [23, 24]. Data analysis concerning the $\mathrm{PM}_{10}$ concentrations in Silesian cities, conducted by Kowalski et al., has proved that a reduction of short-term exposure to $\mathrm{PM}_{10}$ by $5 \mu \mathrm{g} / \mathrm{m}^{3}$ can minimize the number of deaths per year by $2.6-2.75$ per 100000 inhabitants [25].

Numerous scientific reports have confirmed that the increase in the concentration of $10 \mu \mathrm{g} / \mathrm{m}^{3}$ dust in the air shortens the life expectancy of people by 0.64 to 1.37 years (1.11 years in the Netherlands, 1.37 in Finland, 0.80 in Canada, 0.64 in China, and 0.90 in Spain) [26-28]. The undesirable effects of high concentrations of particulate matter to population health are also confirmed by Li et al., showing that an increase in $\mathrm{PM}_{2,5}$ and $\mathrm{PM}_{10}$ concentration by $10 \mu \mathrm{g} / \mathrm{m}^{3}$ air will increase the percentage of premature deaths for all causes by $0.17 \%$ and $0.15 \%$ [29], which is consistent with other reports in this regard $[30,31]$. 
Inequalities in the health condition of the population, resulting from too high concentrations of dust suspended in the air, can also be expressed using other indicators, e.g. the number of years of life lost (YLL) [32, 33]. According to data from the European Environment Agency (EEA), the value of this measure in Poland is one of the highest in Europe (1520). The lowest values of this indicator have been recorded in Iceland (269) and Sweden (307) [32].

Despite many studies on the toxicity of dioxins, polychlorinated biphenyls and their congeners, there is little information in the scientific literature on the relationship between air pollution by chlorinated persistent organic compounds and the life expectancy of society.

The analysis showed that reducing air pollution with dioxin-like PCB compounds by $4.3 \mathrm{fg} \mathrm{I}-\mathrm{TEQ} / \mathrm{m}^{3}$ air, and non-dioxin-like PCBs compounds by $17.5 \mathrm{pg} / \mathrm{m}^{3}$ air can extend men's life by about 8 and 7 months, respectively. In addition, reducing air pollution with dioxin-like PCB compounds by $4.3 \mathrm{fg} \mathrm{I}-\mathrm{TEQ} / \mathrm{m}^{3}$ air can extend women's lives by up to one year.

Research carried out by Dziubanek et al. in 12 Silesian cities showed that the reduction of PCDD/Fs and dl-PCBs of $10 \mathrm{fg}$ I-TEQ $/ \mathrm{m}^{3}$ could extend life expectancy of women by approximately 4 months (0.3 years) [34].

\section{Conclusions}

According to the studies, in search of the relationship between exposure to air pollution and life length, the actual life length (without deaths caused by external causes) should be taken into account, not commonly used average life expectancy.

The use of a multiple regression model in studies on the effects of long-term population exposure to dust pollutants has demonstrated the importance of $\mathrm{PM}_{10}$, dl-PCBs and ndl-PCBs in inhalation effects on life lengths of women and men.

\section{Acknowledgements}

Our research was supported by the Medical University of Silesia, Poland by grant Nos. KNW-2-Z08/ D/7/N and KNW-1-117/N/8/Z.

\section{Conflict of Interest}

The authors declare no conflict of interest.

\section{References}

1. The European health report 2009. Health and health system. Copenhagen: European Regional Office WHO,
2009. Available online: http://www.euro.who.int/ data/assets/pdf_file/0009/82386/E93103.pdf (accessed on 14.10.2018)

2. MARCHWIŃSKA-WYRWAE E., HAJOK I., DZIUBANEK G., PIEKUT A., RUSIN M., OLEKSIUK K., BARANOWSKA R., ZŁOTKOWSKA R. The relationship between the state of health of the population and the quality of the environment characterized by air pollution. In Aspects of public health; Muc-Wierzgoń M., Kokot T., Medical University of Silesia in Katowice: Katowice, Poland, 48, 2012 [In Polish].

3. HOLZER J.Z. Demography. Polskie Wydawnictwo Ekonomiczne S.A.: Warszawa, Poland, 2003 [In Polish].

4. Central Statistical Office of Poland, Department of Demographic and Labor Market Research. Life expectancy in 2014. Central Statistical Office of Poland: Warszawa, Poland, 2015 [In Polish].

5. World Health Organization. International Statistical Classification of Diseases and Related Health Problems 10th Revision, 2016 Available online: http://apps.who. int/classifications/icd10/browse/2016/en (accessed on 14.10.2018)

6. Central Statistical Office of Poland, Department of Demographic and Labor Market Research. Life expectancy in 2015. Central Statistical Office of Poland: Warszawa, Poland, 2016 [In Polish].

7. Eurostat. Mortality and life expectancy statistics. October 2018. Available online: http://ec.europa.eu/eurostat/ statistics-explained/index.php/Mortality_and_life_ expectancy_statistics (accessed on 14.10.2018)

8. National Institute of Public Health - National Institute of Hygiene. The health situation of the Polish population. National Institute of Public Health - National Institute of Hygiene: Warszawa, Poland, 2008 [In Polish].

9. MARCHWIŃSKA-WYRWAE E., DZIUBANEK G., HAJOK I., RUSIN M., OLEKSIUK K., KUBASIAK M. Impact of air pollution on public health. Rijeka: InTech, 3, 2011.

10. World Health Organization. Health effects of particulate matter. Policy implications for countries in eastern Europe, Caucasus and central Asia. Copenhagen: WHO Regional Office for Europe, 2013.

11. Central Statistical Office of Poland. Local Database. Available online: https://bdl.stat.gov.pl/BDL/dane/ podgrup/temat (accessed on 14.10.2018)

12. World Health Organization. Global Health Observatory data repository Life expectancy and Healthy life expectancy. Data by country Available online:http:// apps.who.int/gho/data/view.main.SDG2016LEXv?lang=en (accessed on 14.10.2018)

13. RAMOS R.G., OLDEN K. G. Environment Interactions in the Development of Complex Disease Phenotypes. Int $\mathrm{J}$ Environ Res Public Health, 5 (1), 4, 2008.

14. Revihaap. Review of evidence on health aspects of air pollution - REVIHAAP. WHO Regional Office for Europe, 2013.

15. POPE C.A., BURNETT R.T., THURSTON G.D., THUN M.J., CALLE E.E., KREWSKI D., GODLESKI J.J. Cardiovascular mortality and long-term exposure to particulate air pollution. Circulation 109 (1), 71, 2004.

16. ARCEO E., HANNA R., OLIVA P. Does the effect of pollution on infant mortality differ between developing and developed countries? Evidence from Mexico City. Econ. J. 126 (591), 257, 2016. 
17. BEATTY T.K., SHIMSHACK J.P. Air pollution and children's respiratory health: a cohort analysis. J. Environ. Econ. Manag. 67 (1), 39, 2014.

18. World Health Organization. Ambient (outdoor) air quality and health Available online: http://www.who.int/en/news$\mathrm{room} /$ fact-sheets/detail/ambient-(outdoor)-air-quality-andhealth (accessed on 14.10.2018)

19. DZIUBANEK G., SPYCHAŁA A., MARCHWIŃSKAWYRWAE E., RUSIN M., HAJOK I., ĆWIELĄGDRABEK M., PIEKUT A. Long-term exposure to urban air pollution and the relationship with life expectancy in cohort of 3.5 million people in Silesia. Sci Total Environ. 580, 1, 2017.

20. PASCAL M., CORSO M., CHANEL O., DECLERCQ C., BADALONI C., CESARONI G., HENSCHEL S., MEISTER K., HALUZA D., MARTIN-OLMEDO P., MEDINA S. Assessing the public health impacts of urban air pollution in 25 European cities: results of the Aphekom project. Sci Total Environ. 449, 390, 2013.

21. ETCHIE T.O., ETCHIE A.T., ADEWUYI G.O., PILLARISETTI A., SIVANESAN S., KRISHNAMURTHI K., ARORA N.K. The gains in life expectancy by ambient PM2.5 pollution reductions in localities in Nigeria. Environ Pollut. 236, 146, 2018.

22. ETCHIE T.O., SIVANESAN S., ADEWUYI G.O., KRISHNAMURTHI K., RAO P.S., ETCHIE A.T, PILLARISETTI A., ARORA N.K., SMITH K.R. The health burden and economic costs averted by ambient $\mathrm{PM}_{25}$ pollution reductions in Nagpur. India. Environ. Int., 102, 145, 2017.

23. POPE C.A. 3RD, EZZATI M., DOCKERY D.W. Tradeoffs between income, air pollution and life expectancy: Brief report on the US experience, 1980-2000 Environ Res. 142, 591, 2015.

24. POPE C.A., EZZATI M., DOCKERY D.W. Fineparticulate air pollution and life expectancy in the United States. N Engl J Med. 360 (4), 376, 2009.

25. KOWALSKI M., KOWALSKA K., KOWALSKA M. Health benefits related to the reduction of pm concentration in ambient air, Silesian Voivodeship, Poland Int J Occup Med Environ Health. 29 (2), 209, 2016.

26. KREWSKI D. Evaluating the effects of ambient air pollution on life expectancy. New Engl J Med, 360, 413, 2009.
27. EBENSTEIN A., FANB M., GREENSTONEC M., HE G., ZHOU M. New evidence on the impact of sustained exposure to air pollution on life expectancy from China's Huai River Policy. Proc Natl Acad Sci USA. 114 (39), 10384, 2017.

28. KEIJZER C., AGIS D., AMBRÓS A., ARÉVALO G., BALDASANO J.M., BANDE S., BARRERA-GÓMEZ J., BENACH J., CIRACH M., DADVAND P., GHIGO S., MARTINEZ-SOLANAS Ė., NIEUWENHUIJSEN M., CADUM E., BASAGAÑA $X$. The association of air pollution and greenness with mortality and life expectancy in Spain: A small-area study. Environ Intel 99, 170, 2017.

29. LI G., XUE M., ZENG Q., CAI Y., PAN X., MENG Q. Association between fine ambient particulate matter and daily total mortality: An analysis from 160 communities of China. Sci Total Environ 599-600, 108, 2017.

30. CHEN R., KAN H., CHEN B., HUANG W., BAI Z., SONG G., PAN G. Association of particulate air pollution with daily mortality: the China air pollution and health effects study. Am. J. Epidemiol. 175, 1173, 2012.

31. LU F., XU D., CHEN Y., DONG S., GUO C., JIANG $\mathrm{X}$., ZHENG X. Systematic review and metaanalysis of the adverse health effects of ambient $\mathrm{PM}_{2.5}$ and $\mathrm{PM}_{10}$ pollution in the Chinese population. Environ. Res. 136, 196, 2015.

32. European Environment Agency. Years of life lost attributable to air pollution in 2013. Available online: https://www.eea.europa.eu/highlights/strongermeasuresneeded/table-10-2 (accessed on 14.10.2018).

33. HUANG J., PAN X., GUO X., LI G. Impacts of air pollution wave on years of life lost: A crucial way to communicate the health risks of air pollution to the public. Environ Int. 113, 42, 2018.

34. DZIUBANEK G., MARCHWIŃSKA-WYRWAE E., ĆWIELĄG-DRABEK M., SPYCHAŁA A., RUSIN M., PIEKUT A., HAJOK I. Preliminary study of possible relationships between exposure to $\mathrm{PCDD} / \mathrm{Fs}$ and dl-PCBs in ambient air and the length of life of people. Sci Total Environ. 598, 129, 2017. 